\title{
The zootechnical applications of biotechnology in animal reproduction: current methods and perspectives
}

\author{
Michel THIBIER* \\ Directeur Général de l'Enseignement et de la Recherche, Ministère de l'Agriculture, de l'Alimentation, \\ de la Pêche et des Affaires Rurales, 1 ter rue de Lowendal, 75007 Paris, France
}

\begin{abstract}
The development of the four generations of Reproductive Biotechnology, particularly in cattle and since the last world war, represents one of the best examples of the success story of technology transfer. This review will only refer to the first three generations and will not deal with nuclear transfer nor transgenesis. Based on sound so-called "finalised" research, Artificial Insemination first, then in vivo collected embryo transfer and later in vitro fertilised embryo transfer have been implemented worldwide. Each of these Biotechnologies has many advantages and limitations. In addition to the specificity of each of them, one major point is that farmers and breeders may choose either collectively or individually, the best technology to be used in order to achieve the goals they have set for their industry. It is noteworthy that these technologies have been able to match with the economics demands over the last decades and yet are in a very good capacity to respond to the contemporary demand of sustainable development. In this context, there are further advantages such as potentially contributing to maintaining biodiversity or allowing preservation ex situ of genes otherwise threatened to extinction.
\end{abstract}

farm animals / reproduction / reproductive technologies / artificial insemination / embryo transfer / in vitro fertilization

Preamble: It is with great emotion that I am dedicating this modest contribution to my Professor and teacher, Charles Thibault, who up to my most recent responsibilities, had always found a way to encourage me, since my DEA, encouraging me to take my studies back up after having an activity in veterinary practice, including my departure for the United States then to the Laboratoire de l'Union Nationale des Coopératives d'Insémination Artificielle at Maisons-Alfort. I owe him infinite gratitude.

\section{INTRODUCTION}

Reproduction Biotechnology is without doubt one of the most emblematic products of finalised research in the domain of living sciences and in that of zootechnology. It has left a decisive mark on the evolution of farming over these last sixty years, as much as the considerable progress that has been made during this period in the field of feeding of domestic animals. The first generation of reproduction biotechnology developed on the field, born from the research performed before the Second World War, is

\footnotetext{
* Corresponding author: michel.thibier@agriculture.gouv.fr
} 


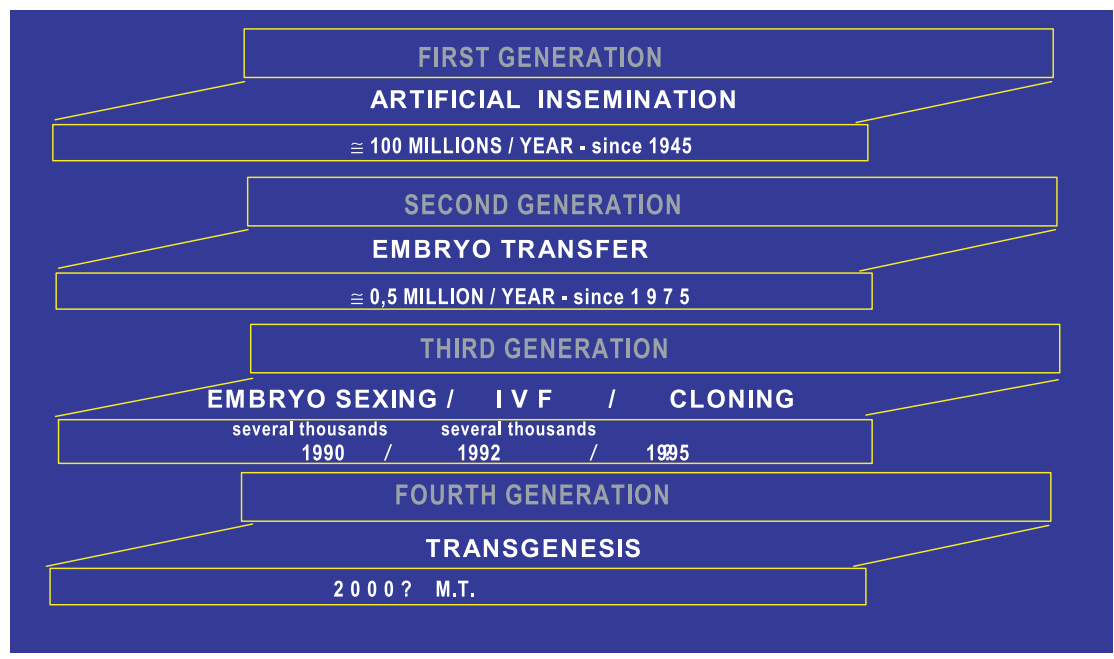

Figure 1. Modern reproductive biotechnologies and trade of germ plasm. The reproductive biotechnologies (from [1]).

that of artificial insemination. This technology has been followed by four generations including embryo transfer, in vitro fertilisation, sexing of embryos and finally later nuclear transfer and transgenesis. Figure 1 illustrates this evolution as presented by the author in 1990 [1]. The number of animals overall implicated in these techniques at the dawn of the last ten years of the last century are given as well as, and especially, what is the most important 15 years later - the prediction of an era of the development of the most recent generations. Even though some of these elements are exact, others have had different destinies than those predicted at the dawn of the last decade. This gives one a distant look on the impact, which is considerable, of these technologies on breeding in the world and on the revenues and the great economic developments of breeders in developed countries. One can also remark that during the second half of the twentieth century, Charles Thibault's research group made a more than significant contribution to the progress in the knowledge and in its pertinent use (often decisive) at INRA, first in Jouy-en-Josas then in Touraine, Auvergne or in Ille-de-France.

I cannot forget to remind, and this is important in order to understand the rapid use of all these techniques of zootechnology by breeders, the important changes that have occurred in an international and economic context since the glorious thirties after the last world war and up to the most recent aspects of globalisation. This evolution tends to make the planet a village like that which could have existed in 1945. Since it is more difficult to "manage a bull" or even a ram from the "Terre de feu" to Yokohama for example, reproduction biotechnologies now play this role which consists in making available to all breeders in the world, gametes from reproducing animals of their choice, wherever they are located in the planet "village".

The aim of this contribution is to evoke several strong points relative to the development of zootechnology in the first three generations. I will let Y Heyman speak of the most recent generation. We will evoke artificial insemination (AI), transfer of 
Table I. Numbers of breedable females and of first inseminations and overall impact of AI in responding countries and according to regions.

\begin{tabular}{|c|c|c|c|}
\hline Regions & $\begin{array}{l}\text { Total females of breeding age } \\
\text {-A- } \\
\text { (40\% of total cattle and buffaloes) }\end{array}$ & $\begin{array}{c}\text { Total first service } \mathrm{AI} \\
-\mathrm{B}- \\
(\% \text { from total first AI's) }\end{array}$ & $\begin{array}{c}\text { Impact ratio } \\
\mathrm{B} / \mathrm{A} \times 100 \\
\%\end{array}$ \\
\hline Africa & 51577000 & $\begin{array}{c}870892 \\
(0.8 \%)\end{array}$ & 1.68 \\
\hline North America & 45206000 & $\begin{array}{c}11203880 \\
(10.2 \%)\end{array}$ & 24.8 \\
\hline South America & 124460000 & $\begin{array}{c}1366678 \\
(1.2 \%)\end{array}$ & 1.09 \\
\hline Far East & 236850000 & $\begin{array}{c}58181005 \\
(52.7 \%)\end{array}$ & 24.56 \\
\hline Near East & 23433000 & $\begin{array}{c}1068991 \\
(0.9 \%)\end{array}$ & 4,55 \\
\hline Europe & 61750000 & $\begin{array}{c}37738142 \\
(34.2 \%)\end{array}$ & 61,11 \\
\hline Total & 543276000 & $\begin{array}{c}110429588 \\
(100 \%)\end{array}$ & 20,32 \\
\hline
\end{tabular}

embryos collected in vivo (ET) and in vitro fertilisation (IVF).

\section{THE FIRST GENERATION: ARTIFICIAL INSEMINATION}

Developed on farms at the end of the Second World War in cattle, it has since been largely developed worldwide in this species and has been extended to most domestic species, notably in pigs. Table I shows the approximate number of females inseminated, more than 100 millions of females at a reproducing age, which represents around a fifth of the totality of this population. One can see that a huge market remains... However, on the contrary to preconceived ideas, this technology has developed the most in Asia and it is also on this continent as well as in South America that progress has been the greatest. Even though the number of AI's is the most modest in small ruminants, over the last fifteen years there has been an increase in the number of AI in pigs with more than 40 million pigs inseminated annually. Freezing, as early as the 1950s for cattle and later for other spe- cies, has contributed to this large development, allowing a delay in time and space and an easier use of the semen. Fresh semen has not necessarily been condemned and participates along with frozen semen in the three cardinal virtues of this technology: its sanitary advantage, genetic improvement generated for future generations and the possible control of reproduction, not including the higher ease brought for the management of male reproducing animals which is not always easy in all breeding structures.

The improvement and widening of the potential inseminated population are different depending on whether a developed or developing country is implicated. For developing countries, as was underlined at an FAO seminar at Banjul (Gambia) organised by our colleagues $\mathrm{D}$. Chupin and $\mathrm{H}$. Wagner, we had the chance of showing how much the use of AI in cattle in these countries, notably in Africa, involved an "integrated" AI in the socio-economic landscape [2]. For developed countries, the main challenge is to contribute, using the technology, to the improvement of fertility rates, especially in cattle. For this, pigs can be considered as an example. Indeed, it is not rare to 
Table II. Overall activity of in vivo derived embryos in 2002 [9] - Number of transferred embryos.

\begin{tabular}{lccc}
\hline Continents & Numbers & Continents & Numbers \\
\hline Africa & $13342(2.7 \%)$ & Asia & $92412(17.2 \%)$ \\
N America & $189124(34.7 \%)$ & Europe & $90371(16.8 \%)$ \\
S America & $119124(22.2 \%)$ & Oceania & $15314(6.4 \%)$ \\
& & Total & 538312 \\
\hline
\end{tabular}

observe fertility rates of 90-95\% with fresh semen and $80 \%$ with frozen semen [3]. In cattle, the main challenge is that of reducing early embryo death as Humblot [4] suggests.

AI has the best cost benefit amongst all reproduction technologies and this conjugated with its technical success, explains the general craze for this technique. It is clearly the first tool to be used by the farmer. Two factors, however, are limiting: that of a mediocre fertility - sometimes being very poor in unfavourable environments (humid tropical regions for example) -, and the difficulty to have access to this biotechnology in herds raised in extensive conditions: ranching where cattle for meat are exploited in a more traditional way. A very important effort must be made on both of these limiting factors.

The arrival on the market in the near future of presexed semen - when the cost will be lower - should change the interest that some farmers have for this technique. However, this may not improve the fertility rate and particular attention to this will be one of the keys to its success.

\section{THE SECOND GENERATION: EMBRYO TRANSFER COLLECTED IN VIVO}

This second generation is more recent and has been used on farms for thirty years. The cost of the investment for the operators and farmers is higher than that of AI and this explains, in part, its less frequent use. The number of embryos transferred in cattle is given in Table II. More than 500000 cattle embryos collected in vivo are transferred annually and this is probably an underestimate since it is difficult to obtain statistics in some regions of the world such as China or India. North America includes more than one-third of the transferred embryos and South America (notably Brazil) almost one forth. This technique is attracting, allowing the transfer in space and time since zygotes, and no longer gametes, can be frozen with success. However, it does have its limits, which are not so much related to the technique itself but rather to the number of embryos that can be transferred per female and per treatment. This is true for all species (and especially for the mare even if interesting progress has been made in recent months). In cattle, the world average is approximately only six embryos per female donor and per treatment. The rate of gestation of approximately $50 \%$ for frozen embryos only multiplies by 2.5 the number of offspring issued from such a female donor. In addition, approximately $20-25 \%$ of females do not respond to the super-ovulation treatment. Theses animals cannot be the object of demultiplication of their descendants by such technology. Finally, this percent of non-response is difficult to predict as long as a first trial has not been undertaken.

The rates of gestation given in Table III issued from French and Canadian data are stable and are of approximately $60 \%$ for transferred fresh embryos. They are 10 points lower for frozen embryos. Only a small margin for improvement exists and only when the trials are led with great care.

The future of this technology is guaranteed. It is included in genetic improvement projects and surprisingly, the majority of AI 
Table III. Mean pregnancy rates for in vivo derived embryo transfer.

\begin{tabular}{lccc}
\hline $\begin{array}{c}\text { Embryo Pregnancy } \\
\text { rate }\end{array}$ & $\begin{array}{c}\text { No. of } \\
\text { transfers }\end{array}$ & References \\
\hline Fresh & $60 \%$ & & $\begin{array}{c}\text { Nibart and Humblot } \\
{[10]}\end{array}$ \\
& $60.8 \%$ & 23569 & $\begin{array}{c}\text { Mapletoft [11] } \\
\text { Frozen }\end{array}$ \\
& $50 \%$ & & $\begin{array}{c}\text { Nibart and Humblot } \\
{[10]}\end{array}$ \\
& $48 \%$ & 8042 & $\begin{array}{c}\text { Mapletoft [11] } \\
\text { Humblot [12] }\end{array}$ \\
\hline
\end{tabular}

bulls in the world come from transferred embryos. This second generation is a privileged way to conserve ex situ genetic collections of species threatened by extinction. Finally, it is the safest way to exchange genes from one region to another or from one continent to another. It contributes to the globalisation of genetic exchange.

\section{THE THIRD GENERATION: IN VITRO FERTILISATION}

At the end of the 1980s, there was intensive research done in Charles Thibault's laboratory on small ruminants and in cattle $[5,6]$. It is important to remember that the first in vitro fertilisation followed by births was performed in the rabbit by Charles Thibault's research group at Jouy-en-Josas, over forty years ago [7]. The first calves born after in vitro fertilisation appeared during the 1980s. Even though the first successful trials reported by Ben Brackett at the beginning of these years only included the fertilisation step performed in vitro, this biotechnology used on domestic animals in vitro very rapidly included the first steps in their whole sequence: in vitro maturation of oocytes collected at the slaughterhouse or after in vivo samplings, maturation of male gametes in vitro, encounter of gametes and fertilisation then and more importantly, the in vitro culture of zygotes and embryos up to the stage at which the embryo produced in vitro could be transferred (morula or blastocyst stage). Using this third generation technique requires correctly equipped laboratories and can thus only be collective; AI cooperatives are well situated for the development of this technique. This was realised in France and Europe in the previous decade, but it is really in Japan and in Brazil that this technique has really expanded. These two countries alone account for almost one-half of all the transferred in vitro fertilised embryos. Table IV gives statistical data collected in 2002. It first includes data on the large number of in vitro fertilised oocytes producing transferable embryos (around 200000 in the world). However, only barely one-half of the transferred embryos give an irregular or mediocre yield at each step of this procedure.

This biotechnology as a technique has numerous advantages. It allows collecting the oocytes very easily at the slaughterhouse. This procedure has, however, some important sanitary constraints and the International Embryo Transfer Society (IETS) by the intermediary of its scientific committee (Health and Sanitary Advisory Commitee-HASAC) is in the process of writing directives in order to avoid that pathogenic agents possibly be associated with such embryos coming from oocytes collected at the slaughterhouse. Indeed, there is a high demand from Asian countries for such

Table IV. Number of in vitro produced bovine embryos transferred [9].

\begin{tabular}{lcccc}
\hline Numbers & $\begin{array}{c}\text { Transferable } \\
\text { embryos }\end{array}$ & & Transferred embryos & \\
\hline \multirow{2}{*}{ Total } & Collected & Fresh & Frozen & Total \\
\hline
\end{tabular}


Table V. Pregnancy rates of fresh and frozen in vitro produced bovine embryos in France.

\begin{tabular}{lccc}
\hline Embryos & $\begin{array}{c}\text { Early pregnancy rate } \\
\text { (Day 35) }\end{array}$ & $\begin{array}{c}\text { Pregnancy rate } \\
\text { (Day 90) }\end{array}$ & Reference \\
\hline Fresh & & & \\
Experimental farm & $57 \%$ & $52.8 \%$ & $\begin{array}{c}\text { Guyader-Joly et al. [13] } \\
\text { Commercial farm }\end{array}$ \\
Frozen & & $54.5 \%$ & Marquant-LeGuienne et al. [14] \\
(Selected grade 1) & $69.8 \%$ & $51 \%$ & Marquant-LeGuienne et al. [14] \\
\hline
\end{tabular}

embryos whose cost is extremely low, which explains their current attractiveness. An alternative to slaughterhouse collection exists; in cattle, this implicates in vivo ovarian punction, a transvaginal technique called "ovum pick up", at all stages of genital life in the female, including gestation. Such samplings can be frequently repeated and some research teams perform such samplings two or even three times a week. This technique has two advantages: (i) to free oneself of the variability of response to the treatments of super-ovulation in the context of in vivo collection of embryos and (ii) to be able to obtain a much higher number of oocytes per female than in the preceding technique since frequent repetition of such oocyte sampling is possible.

One of the delicate phases is that of the culture of in vitro fertilised embryos. Two groups of techniques exist: the most frequently used technique is that of in vitro culture either in a synthetic medium or in co-culture with different primary or stabilised cell lines. A second technique, still used with frozen embryos, is that of the passage of the in vitro fertilised bovine embryo, in the genital tract of a ewe during the five-to-six days that are necessary to its development before its transfer to the genital tract of the female bovine recipient. This technique has been largely developed by an Italian research group (C. Galli et al.).

Another big advantage of this technique is that it allows to complete, in a relatively convenient and practical manner, production by other associated technologies, in particular the prenatal diagnostic such as that of sex, bi-section, nuclear transfer as a source of enucleated gametes etc.

A factor limiting the development of this technique notably in countries where the cost of labour is high, comes from the variability of the rate of gestation, even for fresh transferred embryos that associated with high investments in terms of laboratory competence, lead to a high final cost of the operation.

A second major current limiting factor is associated with freezing: the gestation rates of frozen embryos are on average much lower than those of fresh embryos produced in vitro. For the moment, this reduces in an important way the interest of this third generation of reproduction biotechnology.

The results published by the UNCEIA laboratory (Tab. V) are interesting to observe. These data show that it is possible to obtain confirmed gestation rates over $50 \%$ but only in optimal and well-controlled conditions, which is not always possible in commercial herds. In Table V, embryo gestation rates from embryos produced in vitro and frozen (on a small number of animals but in optimal conditions) are above 50\%. It would, however, not be reasonable to extrapolate to the field and in routine, such rates given the current state of our knowledge. It is paradoxical to observe that little progress has been made over the last fifteen years in the controlling of frozen embryos produced in vitro, especially since many studies have been carried out to understand the underlining reason(s). 
Clearly, this technology has an important potential for the future, in relation with all biotechnologies. However, and notably in developed countries, its development is slowed down due to the cost of investments, which is higher than that of the previous generations, and the gestation rates that are routinely still too low after freezing. It may seem paradoxical to affirm, but reality shows, that the major development of this third generation is situated in developing countries from low cost embryos.

It is important that the sanitary rules set by the IETS and OIE, limiting the transmission of pathogenic agents with embryos, must not be minimised. In a large number of developed countries, including those of the European Union and North America, strict rules have been set for the use of this technology. These countries have adopted the concept of specific groups officially authorised by veterinarian service officials, selected from a certain number of criteria and duly verified technical elements. Only such groups can give a sanitary guarantee for the transfer of embryos produced in vitro.

This technology requires acquiring additional robustness but it is probable that it will some day be largely used in the world, due to its flexibility, its possibly reduced cost, its important sanitary safety when correct conditions are used. It is also a technology that will be well appreciated for the conservation of species and breeds that are threatened by extinction.

\section{CONCLUSION}

Over the last sixty years, reproduction biotechnologies have shown an exemplary capacity for adaptation. They are a model of transfer of technology between the research laboratory and the field and farms in all countries and continents.

Of course, each new generation brings forth technical complexity with more investments, but they have advantages that were missing with earlier generations. These bio- technologies can thus give a choice to farmers individually or collectively as to the most appropriate technique to be developed in order to reach the fixed objectives in animal production. In addition, these technologies even though they have shown their capacity to fit into the context of economic development, are in the process of showing their at least equal capacity to be incorporated into the objectives of sustainable development when used intelligently to maintain biodiversity and to conserve genes of individual collections otherwise threatened by extinction.

\section{REFERENCES}

[1] Thibier M. New biotechnologies in cattle production. In: 7th Congress of the FAVA 4-7 Novembre 1990, Pattaya (Thaïlande), p 513524.

[2] Thibier M. Analyse critique des services d'insémination artificielle dans les pays en voie de développement. In: Amélioration génétique des Bovins en Afrique de l'Ouest, Etudes FAO, Production et Santé Animales 1993, 110: 91-106; FAO Ed, Rome, Italy.

[3] Eriksson BM, Petersson H, Rodriguez-Martinez H. Field fertility with exported boar semen frozen in the new FlatPack Container. Theriogenology 2002, 58: 1065-1079.

[4] Humblot P. The frequency and variation of embryonic mortality and the use of pregnancy specific proteins to monitor pregnancy failure in ruminants. In: Proc 3rd ESDAR meeting, Reproduction in Domestic Ruminants 2000, Suppl 6, p 19-27.

[5] Le Guienne B, Thibier M. Premiers blastocystes bovins obtenus en totalité in vitro. El Ins 1988, 224: 11-14.

[6] Marquant-Le Guienne B, Humblot P, Thibier M, Thibault C. Evaluation of bull semen fertility by homologous in vitro fertilization tests. Reprod Nutr Develop 1990, 30: 259_ 266.

[7] Thibault C, Dauzier L, Wintenberger S. Étude cytologique de la fécondation in vitro de l'oeuf de la lapine. Comptes Rendus de la Société de Biologie 1954, $\mathrm{N}^{\circ}$ 9-10, p 789-790. 
[8] Thibier M, Wagner HG. World Statistics for artificial insemination in cattle. Livest Prod Sci 2001, 74: 203-212.

[9] Thibier M. A contrasted year from the world activity of the animal embryo transfer industry - A report from the IETS Data Retrieval Committee. IETS Newsletter, 2002, 20: 13-19.

[10] Nibart M, Humblot TP. Pregnancy rates following direct transfer of glycerol sucrose or ethylene glycol cryopreserved bovine embryos. In: Proceedings of the Annual conference of the International Embryo Transfer Society (I.E.T.S.), Nice, France, 2-14 janvier 1997, Theriogenology 1997, 47: 371.

[11] Mapletoft RJ. Personnal communication, 2002.

[12] Humblot P. Use of pregnancy specific proteins and progesterone assays to monitor preg- nancy and determine the timing, frequencies and sources of embryonic mortality in ruminants. Theriogenology 2001, 56: 1417-1433.

[13] Guyader-Joly C, Durand M, Morel A, Ponchon S, Marquant-Le Guienne B, Guérin B, Humblot P. Sources of variation in blastocyst production in a commercial ovum pickup in vitro embryo production program in dairy cattle. In: Annual Conference of the International Embryo Transfer Society (IETS), Maastricht, Pays-Bas, 9-11 janvier 2000, Theriogenology 2000, 53: 355.

[14] Marquant-Le Guienne B, Guyader-Joly C, Ponchon S, Delalleau N, Florin B, Ede P, Ponsart C, Guérin B, Humblot P. Results of in vitro production in a commercial ovum pickup program. In: Annual Conference of the IETS, Omaha, Nebraska, USA, 13-16 janvier 2001, Theriogenology 2001, 55: 433. 